\title{
Coastal cliff rock mass weakening of Chalk and the impact of salt water
}

\author{
James A. Lawrence PhD \\ Senior Lecturer, Department of Civil and Environmental Engineering, \\ Imperial College, London, UK (corresponding author: j.lawrence@imperial. \\ ac.uk) (Orcid:0000-0002-9781-817X) \\ Richard Spence MSc \\ Geotechnical Engineer, Mott MacDonald, Sheffield, UK \\ Rory N. Mortimore PhD \\ Managing Director, ChalkRock Ltd, Lewes, UK
}

Martin Eade MEng

Highways Engineer, Brighton and Hove City Council, Hove, UK

Simon H. Bottrell PhD

Head of School, School of Earth and Environment, University of Leeds, Leeds, UK

The relationship between salt water and the strength of Chalk forming the coastal cliffs of northwest Europe was investigated. Uniaxial compressive strength (UCS) tests on core samples from three horizontal boreholes drilled at the base of Chalk cliffs in East Sussex, UK, showed the weakest Chalk to be near the cliff face. The UCS nearly doubled over the length of the $9 \mathrm{~m}$ deep boreholes. The UCS results were close to values expected for Chalk of this intact dry density for samples farthest from the cliff face. High chloride concentrations (salt water) of up to $69000 \mathrm{mg} / \mathrm{l}$ were found to be associated with the lowest UCS values closest to the cliff face. Lower chloride concentrations, with values of $1850 \mathrm{mg} / \mathrm{l}$ or less and often with a non-marine origin, were found in the stronger core samples. It can be concluded that the Chalk coastal cliffs in the areas tested became weaker towards the cliff face. This can, in part, be linked to salt water weakening although it is likely that other factors are also contributing to this phenomenon.

\section{Introduction}

The correlation between rock mass characteristics and rates of coastal cliff erosion is well established (e.g. Budetta et al., 2000; Sunamura, 1994). The evolution of a coastal cliff from stable to failure depends on changes in the state of stress within the rock mass as a result of processes acting within the rock mass, either caused by external agencies of sub-aerial and marine origin (Duperret et al., 2005; see Figure 1) or by other factors within the rock mass. Examples of these processes include waves attacking and eroding the base of the cliff and water weakening of the Chalk. Water weakening of Chalk is a controversial issue and many possible different mechanisms have been proposed, including

(a) changes in capillary forces (Delage et al., 1996)

(b) changes in strain in the Chalk between fresh and saline waters (Hellmann et al., 2002)

(c) increased pressure on Chalk grains caused by the attraction of water molecules onto the Chalk surface (Risnes et al., 2005)

(d) chemical dissolution (Heggheim et al., 2005)

(e) sea water as a wettability modifier in Chalk at high temperatures (Austad et al., 2008).

Water weakening of Chalk is thus a complicated issue, with many different mechanisms all playing their part. Goudie et al. (1970) demonstrated the rapid weathering of saltsaturated Chalk and also showed that porosity, saturation coefficients and water absorption capacity all affect the susceptibility of rock to salt weathering (Trenhaile, 1987). Working on Chalk cliffs in northwest Europe, Busby et al. (2004a, 2004b) and Lawrence et al. (2013) measured triaxial compressive strength and used scanning electron microscope analyses to establish the role that saturation with fresh water and salt water had on Chalk strength and thus on cliff stability; similar processes were also reported by Duperret et al. (2005). Busby et al. (2004a, 2004b), Lawrence et al. (2013) and Lawrence and Mortimore (2015) identified salt water weakening in Chalk cliffs and suggested that this was contributing to rock mass weakening, resulting in cliff collapse. Dornbusch (2015) argued that salt water weakening only caused superficial surface flaking such as that identified by Robinson and Jerwood (1987). Lawrence et al. (2013) demonstrated that combined water and salt water weakening effects could lower the intact rock strength of Chalk by over $75 \%$, but they were unable to show how far the salt water weakening was penetrating the cliffs and the effect it was having on the overall rock mass.

To address these issues, field investigations were combined with a comprehensive laboratory testing programme on core samples from three horizontal boreholes drilled into Chalk cliffs at two UK sites on the East Sussex coast: Brighton Marina (grid reference TQ 34516 03111) and the town of Peacehaven (grid reference TQ 39250 01429). The laboratory tests included

(a) index tests to determine the physical properties of the rock

(b) core logging to characterise the Chalk

(c) uniaxial compressive strength (UCS) tests to quantify the extent of weakening 


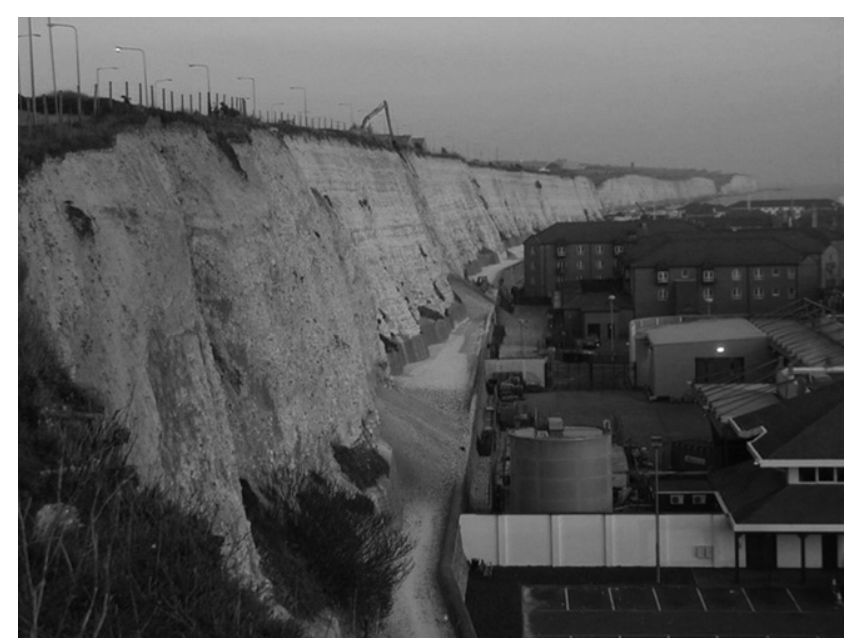

Figure 1. Chalk coastal cliff collapse and remediation along protected sections of coastline behind Brighton Marina, East Sussex, UK (2001)

(d) geochemical elution tests and ion chromatography analyses to establish the salinity profile and origin of the pore water composition for Chalk cliffs in protected and unprotected sections of the coastline.

\section{Boreholes and sample collection}

Three horizontal boreholes were cored at two locations in East Sussex, UK (Figure 2). Two of the boreholes were cored at the eastern end of Brighton Marina (grid reference (GR) 3450 0313) and one just to the west of the town of Peacehaven (GR 3922 0145) (Figure 2). The Brighton Marina cores were drilled on a protected section of cliff (engineered cliff base and face protection including a sea wall), while the Peacehaven core was drilled on a natural cliff section where the lower part of the cliff was exposed to the sea. The boreholes were drilled near the base of the cliff, using air flush to ensure the Chalk pore waters were not contaminated. Each core was approximately $9 \mathrm{~m}$ long.

In addition, surface block samples were collected from the cliff face at each site to substitute for the lack of core available in the first $300 \mathrm{~mm}$ of the cliff face. The cores were stored in plastic liners with wax-sealed end caps to prevent the escape of moisture and the block samples were wrapped in aluminium foil. The chosen method of wrapping in aluminium foil was found to work better than placing in sealed plastic bags, which can make the sample sweat.

\subsection{Research drill sites}

\subsubsection{Brighton Marina}

The Brighton Marina research site is located at the eastern edge of the marina, along a protected section of cliff just above the cliff splash wall. Two drill runs, about $1 \mathrm{~m}$ apart, were taken (Figures 3 and 4).
The site has coastal protection in the form of a sea wall, which is also protected by groynes on the shore platform. The edge of the marina wall has precast concrete rip-rap along the base of the wall to provide further protection. The drill site was located $4.5 \mathrm{~m}$ back from the sea wall, at the base of the cliff face, which is orientated southeast-northwest (Figures 3-5). The site is a predominately relict sediment system and the entire length of the coastline in this area is heavily modified. Long-shore transport travels west to east but is limited by the presence of coastal developments and sea defences (Thorne et al., 2007).

The Brighton Marina research site consists of large cliff sections around $30 \mathrm{~m}$ high, which have been scaled back to decrease the angle of the cliff face and stabilised with rock bolts and netting along the top $5 \mathrm{~m}$ to prevent loose rubble falling onto the undercliff walk. The rock mass appears more fractured with thinner beds of Chalk and a noticeable increase in the amount of grey surface weathering residue compared with the Peacehaven research site. There are signs of surface run-off on the cliff face, marked by grey or brown staining, with no signs of seepage out of the cliff face. The cliff face remains largely unvegetated with some local xerophytic grass types at the cliff base. Stratigraphically, the drill site is in the Newhaven Chalk Formation just above the Brighton Marl near the base of the Old Nore Beds.

The horizontally cored boreholes and block samples (four, approximately $20 \mathrm{~kg}$ each) from the Brighton Marina site are now described, in line with BS EN ISO 14689 (BSI, 2009) and the work of Lord et al. (2002).

\subsubsection{BRIGHTON MARINA - BOREHOLE 1 (BH1)}

The rock here is pure white Newhaven Chalk, of medium density, with some flints, iron staining and inclined conjugate fracture sets.

The core run had two main fracture sets striking $20-60^{\circ}$ to the east and $40-60^{\circ}$ to the northwest. The east dipping fracture set was considerably more prominent than the northwest dipping fracture set, with around $80 \%$ of the fractures belonging to the east dipping set.

The core run was more fractured than $\mathrm{BH} 2$, which ran parallel approximately $1 \mathrm{~m}$ to the east of this core and demonstrates the variability of the Chalk in the region. Rock quality designation (RQD) values varied from $46 \%$ to $67 \%$. The total core recovery for the run was $100 \%$.

\subsubsection{BRIGHTON MARINA - BOREHOLE 2 (BH2)}

The rock here is pure white Newhaven Chalk, of medium density, with some flints, iron staining and inclined conjugate fracture sets. 


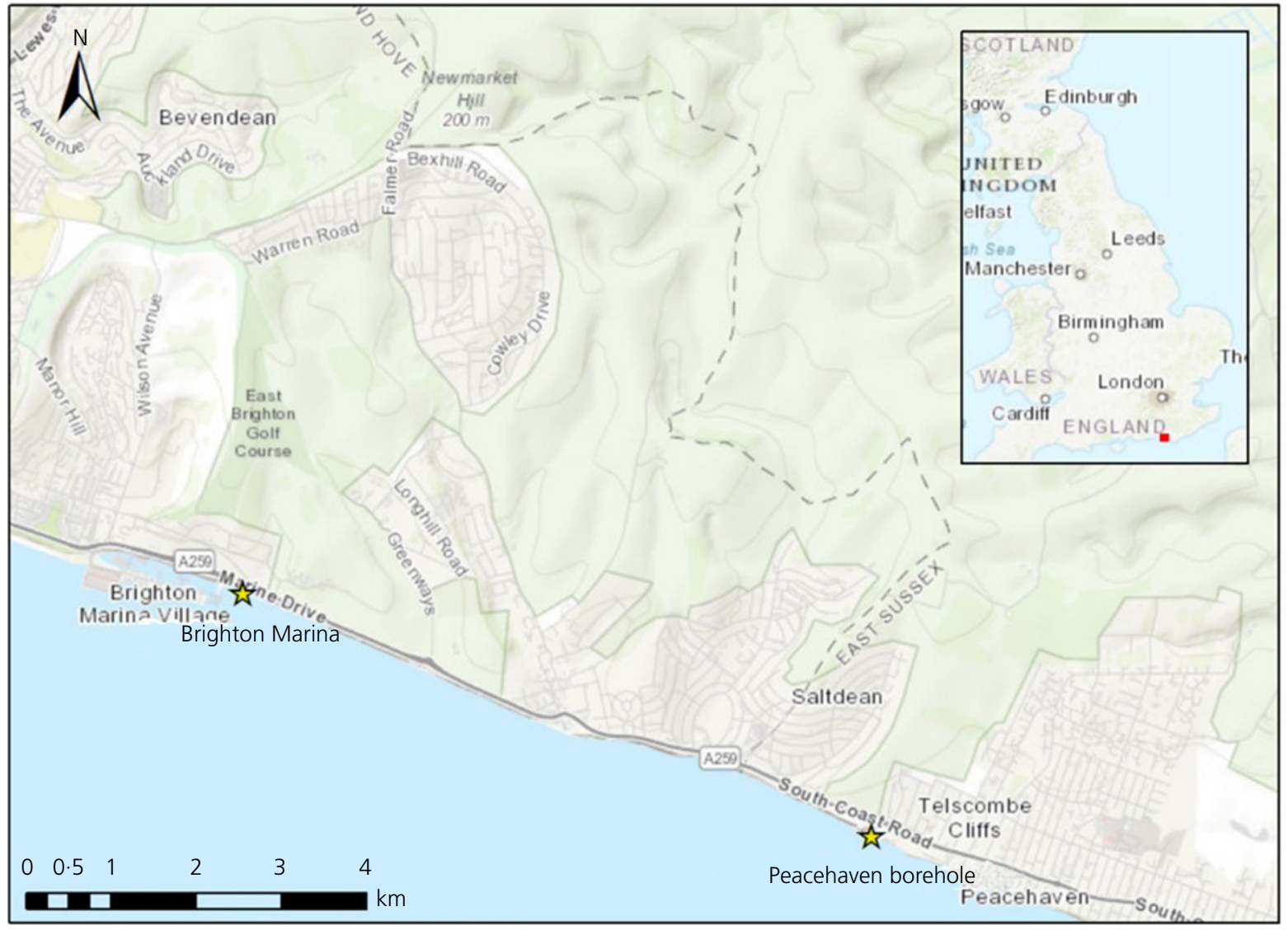

Figure 2. Location of boreholes

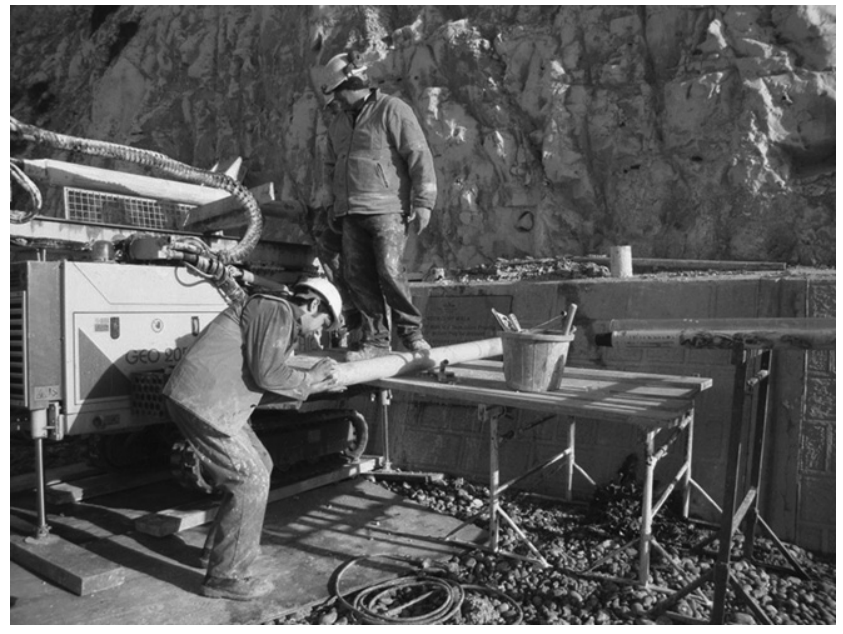

Figure 3. Horizontal core drilling at Brighton Marina (February 2012)

The core log had two main fracture sets striking $20-45^{\circ}$ to the east and $20-70^{\circ}$ to the northwest. These were conjugate joint sets that could be seen in the outcrop dipping steeply into the cliff face.
The core run was made of predominantly competent rock mass that was cut by the two fracture sets. The RQD varied from $53 \%$ to $95 \%$ but most of the core run had an RQD of $80 \%$ or higher and the total core recovery was $100 \%$. A substantial amount of drill-induced fracturing did occur throughout the entire core run, making up around $40 \%$ of the total fractures.

\subsubsection{Peacehaven site}

This borehole site was located on an unprotected section of Chalk sea cliffs near the town of Peacehaven. The borehole was located $5 \mathrm{~km}$ east of the Brighton Marina boreholes and was $3 \mathrm{~m}$ up the cliff face. The site is located close to the axis of the Newhaven Syncline within the Newhaven Chalk Formation just above the Old Nore Marl at the base of the Peacehaven Bed, stratigraphically approximately $27 \mathrm{~m}$ above the Brighton Marina boreholes. The borehole site is shown in Figure 6.

The Peacehaven research site consists of 35-40 m high cliff sections, with no cliff-stabilisation measures so the rocks are in their natural state. The Chalk is soft and pure white in colour; small nodular flints are common in some beds and many fractures are infilled with sheet flints. There was clear evidence that 
Geotechnical Engineering

Volume 171 Issue GE6
Coastal cliff rock mass weakening of

Chalk and the impact of salt water

Lawrence, Spence, Mortimore, Eade and

Bottrell active erosion was taking place due to the complete exposure to tides. The cliff is almost completely unvegetated, with some mosses and lichens present.

The horizontally cored borehole and block samples (three, approximately $15 \mathrm{~kg}$ each) at Peacehaven are now described, in line with BS EN ISO 14689 part 1 (BSI, 2009) and Lord et al. (2002).

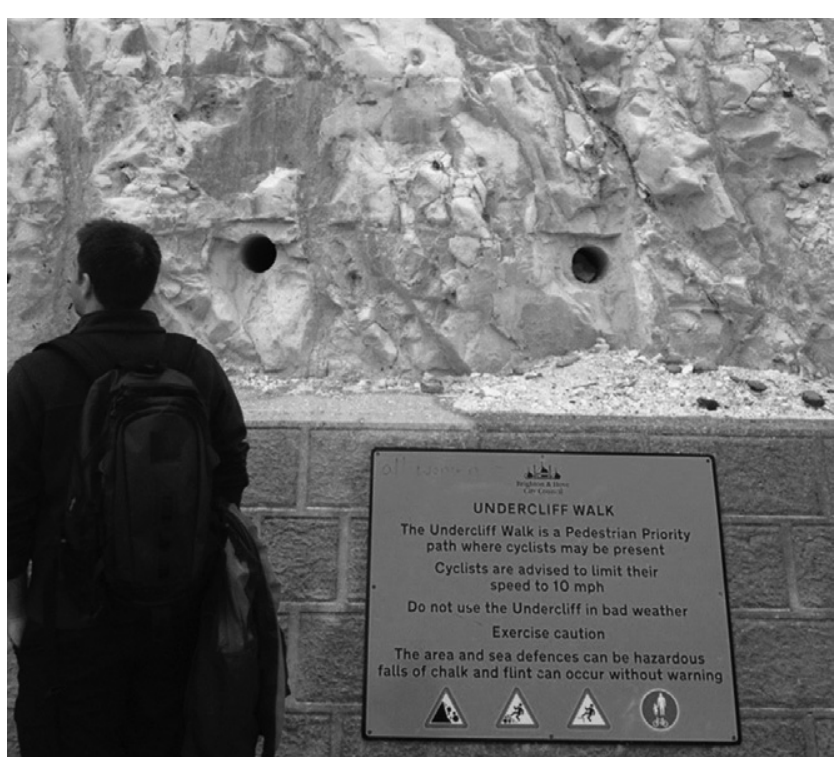

Figure 4. Location of the two drill holes at Brighton Marina (June 2012)

\subsubsection{PEACEHAVEN - BOREHOLE 3 (BH3)}

The rock here is pure white Newhaven Chalk, of medium density, with some flints, marl seams and sub-vertical conjugate joint sets.

The core was drilled in a competent rock mass with a highly fractured section from $3 \cdot 0-4 \cdot 0 \mathrm{~m}$. The two main joints sets were striking $20-40^{\circ}$ to the east and $20-50^{\circ}$ to the northwest, similar to the Brighton Marina fracture orientations. The RQD varied from $7 \%$ to $100 \%$ but all the cores except the $3.0-4.5 \mathrm{~m}$ section exceeded an RQD of $70 \%$. The TCR was $100 \%$. A lesser amount of drilling-induced fracturing was seen in this core run than at Brighton Marina (BH1 and $\mathrm{BH} 2$ ).

\section{Laboratory methods}

Laboratory investigations were undertaken to establish the origin of pore waters, the penetration depth of salt water in the cliff (geochemical analysis) and any changes to the rock properties over the length of the core (strength tests). These were supported by a series of index tests to characterise the rock mass.

\subsection{Index tests}

Index tests of Chalk (intact dry density (IDD), natural moisture content (NMC) and saturated moisture content (SMC)) provide a useful insight into the behaviour of the material and can usually be correlated with point load index, strength tests and porosity (Lord et al., 2002).

IDD, SMC and NMC tests were carried out at $500 \mathrm{~mm}$ intervals along all three core runs. The immersion-in-water method

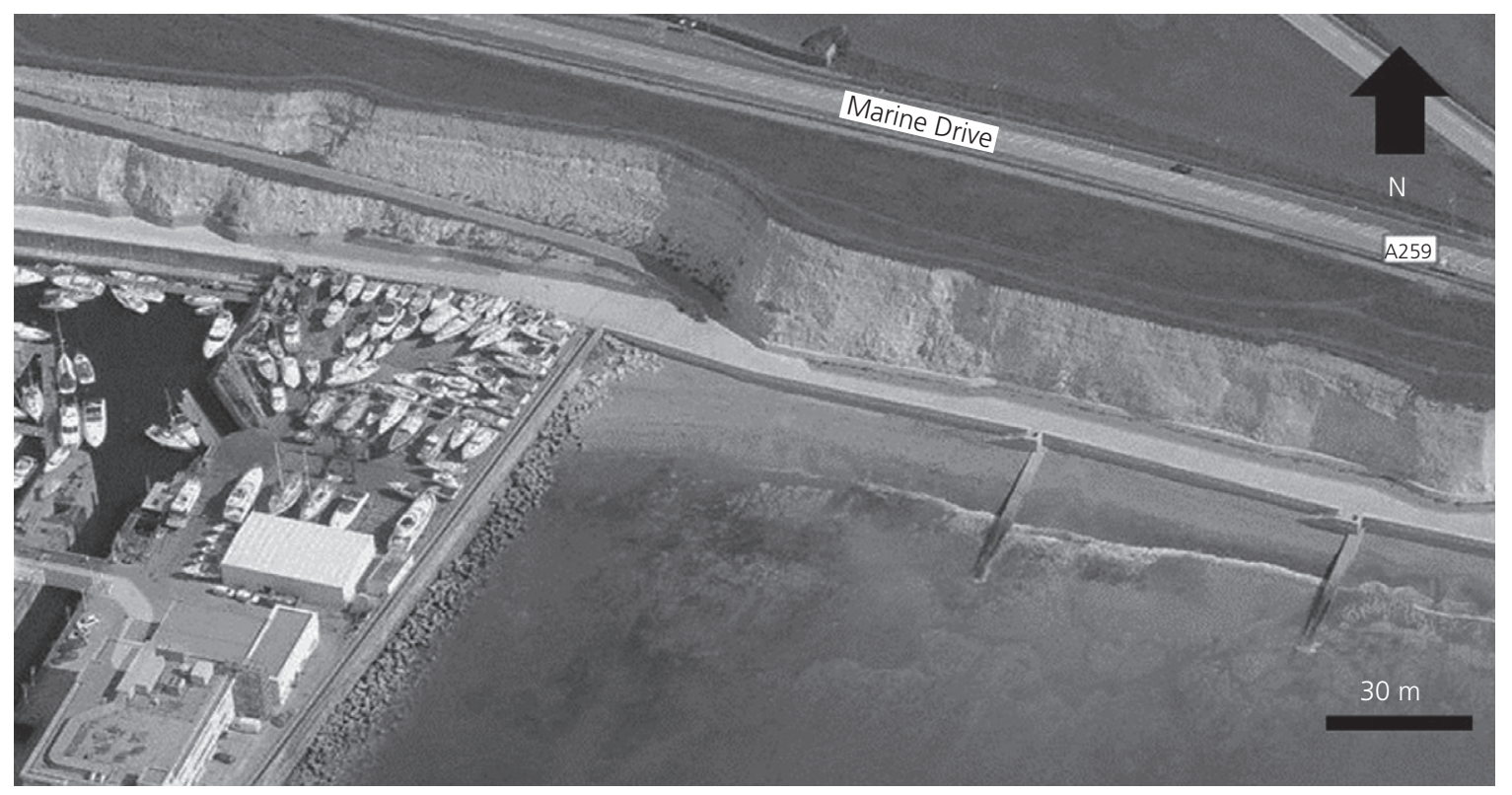

Figure 5. Aerial photo showing Brighton Marina site (Retrieved from Google Earth 2013) 
Coastal cliff rock mass weakening of

Chalk and the impact of salt water

Lawrence, Spence, Mortimore, Eade and Bottrell

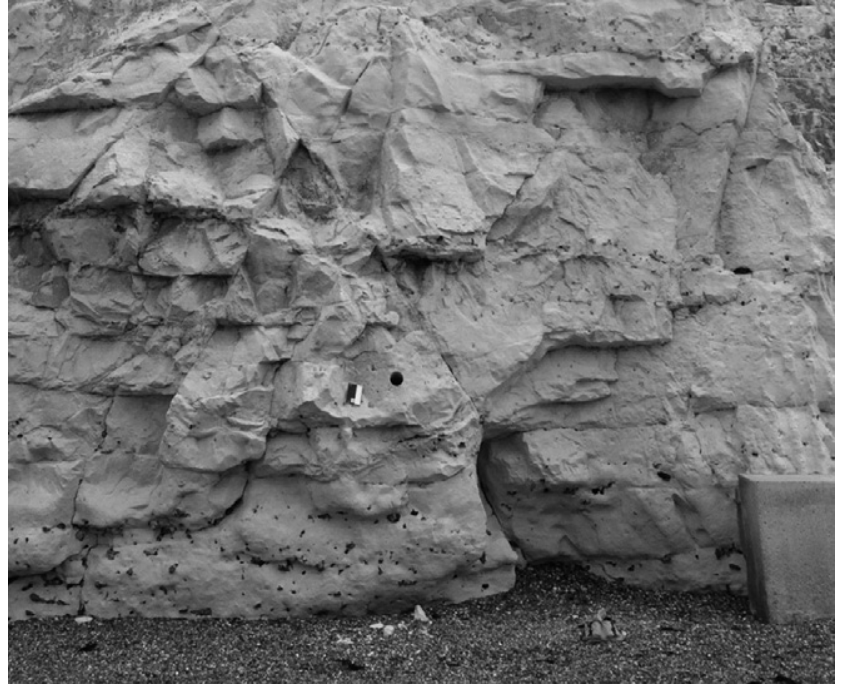

Figure 6. The drill site at Peacehaven; note the inclined conjugate fractures running perpendicular to the cliff (February 2012)

was used to calculate the IDD and SMC of chalk blocks of approximately $100 \mathrm{~g}$ (BS 1377-2:1990 (BSI, 1990)).

The SMC and NMC allow the moisture content of a core profile to be fully understood so that any strength tests conducted will document weakening relating to samples as close to saturation as possible. This ensures that the wettability of Chalk will be factored in to all samples and fluctuations in moisture content will not provide varying strength data relating to moisture content as opposed to salinity.

\subsection{Geomechanical tests}

A laboratory strength testing programme was designed to determine

- the impact salt water weakening was having on the strength of the Chalk

- the degree to which the weakening effects had penetrated the cliff.

UCS tests were carried out on all cores at $0.5 \mathrm{~m}$ intervals by taking $76 \mathrm{~mm} \times 38 \mathrm{~mm}$ samples. All samples were tested at saturation as this replicated the natural conditions found in the rock mass; this was achieved by placing the samples in a desiccator for $2 \mathrm{~h}$ under vacuum with deionised water. As samples were already within 1-2\% moisture content of saturation, $2 \mathrm{~h}$ was deemed sufficient to saturate the samples completely. The salinity of the cores was not assumed to be an issue because $2 \mathrm{~h}$ in the desiccators was not long enough to alter the salinity of the samples significantly. If any salt weakening was to have occurred it should have done so before the samples had been placed in the desiccator.

\subsection{Geochemical analysis - elution testing}

Groundwater analysis was an important issue in the context of this study as 'natural reactions between water and rock give rise to a wide diversity in the mineral character of groundwater. This imparts intrinsic properties such as hardness and softness and salinity' (Edmunds et al., 2003). For these reasons it was decided that alongside chloride analysis to establish the amount of salt in the pore waters, sulfate concentrations should also be measured to give insight into the groundwater regime and origin. Sulfate isotopic composition can be used as a 'fingerprint' for the sulfate source (sea water, groundwater, acid rain etc.).

As already mentioned, the core runs were drilled with air flush to ensure the samples were not contaminated. However, due to errors in the drilling methods, Brighton Marina BH1 was contaminated with some fresh water and therefore only Brighton Marina $\mathrm{BH} 2$ and Peacehaven $\mathrm{BH} 3$ were selected for elution testing.

Chalk samples were prepared at $0,0 \cdot 3,0 \cdot 6,1,2,3,4 \cdot 5$ and $6 \mathrm{~m}$ along each core run. For elution testing, pore water dissolved solids were extracted from the core samples by diffusion exchange with an accurately known volume of milli-Q water and recalculated to original concentrations (Spence et al., 2005). Pore waters were analysed for sulfate and chloride concentrations by ion chromatography (Dionex) and sulfate extracted from leachate as barium sulfate $\left(\mathrm{BaSO}_{4}\right)$ for sulfur isotopic analysis.

\section{Laboratory testing results}

\subsection{Index tests: NMC and SMC}

The results from the index tests (Figures 7 and 8) showed the strong relationship between the NMC and SMC. It can be

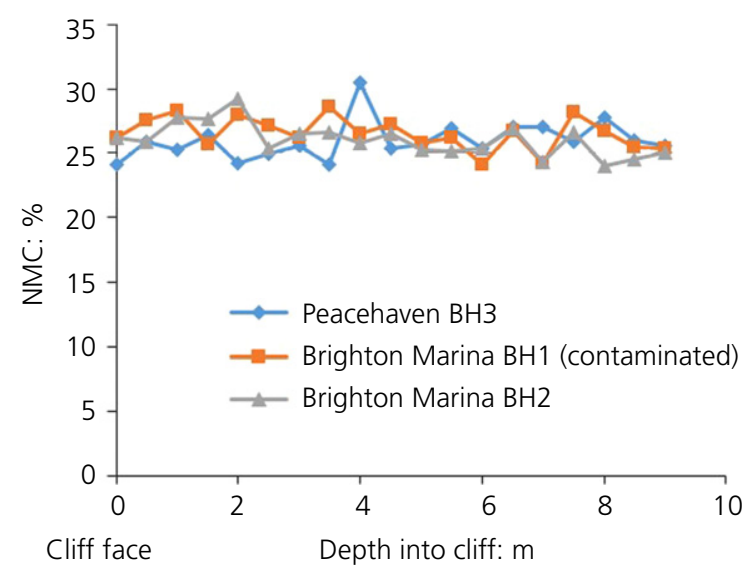

Figure 7. NMC plotted against horizontal depth of all three boreholes. The test results for all three boreholes were very similar and consistent, showing rock at or near saturation regardless of location 
seen from the data that the NMC was very close to the SMC, confirming that the samples were nearly at saturation; this was expected as Mortimore and Fielding (1990) and Mortimore

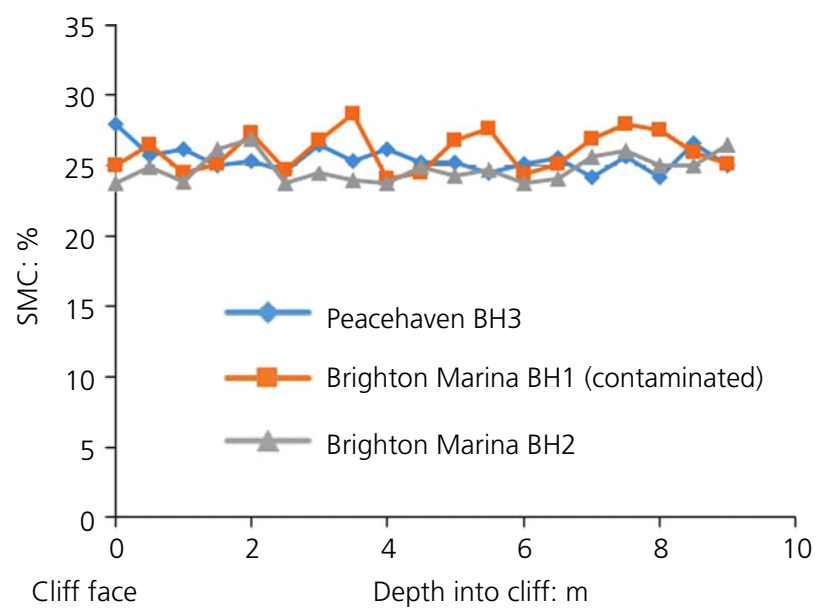

Figure 8. SMC plotted against horizontal depth of all three boreholes. The test results for all three boreholes were very similar and consistent et al. (2004a) showed Chalk tends to be at or near saturation in its natural state. The data also showed very little variation both in the individual drill runs and across the localities, which was expected as all three boreholes were in the Newhaven Chalk Formation (Table 1).

\subsection{Index tests: IDD}

All samples consisted of Newhaven Chalk and there was only a very small variability between locations and within the boreholes (Figure 9 and Table 2). The samples from Brighton Marina (BH1 and $\mathrm{BH} 2$ ) had an IDD that varied in the range 1.52 $1.65 \mathrm{Mg} / \mathrm{m}^{3}$; the average IDD was $1.60 \mathrm{Mg} / \mathrm{m}^{3}$ with an average standard deviation (SD) of $0.02 \mathrm{Mg} / \mathrm{m}^{3}$. Samples collected from the unprotected beach at Peacehaven (BH3) had an IDD that varied from 1.53 to $1.64 \mathrm{Mg} / \mathrm{m}^{3}$; the average IDD was $1.60 \mathrm{Mg} / \mathrm{m}^{3}$ with an average SD of 0.02 . These results class all the samples tested as medium-density, very soft to soft Chalk.

\subsection{Geomechanical strength tests: UCS tests}

Results from the UCS tests showed that the core samples tested from further behind the cliff face tended to have a higher UCS. The Peacehaven core (BH3) showed increases in

Table 1. Average NMC and SMC for each site and the average SD from the average

\begin{tabular}{|c|c|c|c|c|c|c|}
\hline & \multicolumn{2}{|c|}{ Brighton BH1 } & \multicolumn{2}{|c|}{ Brighton $\mathrm{BH} 2$} & \multicolumn{2}{|c|}{ Peacehaven BH3 } \\
\hline & Average & Average SD & Average & Average SD & Average & Average SD \\
\hline NMC: \% & $26 \cdot 53$ & 1.01 & $25 \cdot 98$ & 1.04 & $26 \cdot 02$ & 1.02 \\
\hline SMC: \% & $26 \cdot 01$ & $1 \cdot 24$ & $25 \cdot 45$ & 0.68 & $24 \cdot 79$ & 0.82 \\
\hline
\end{tabular}

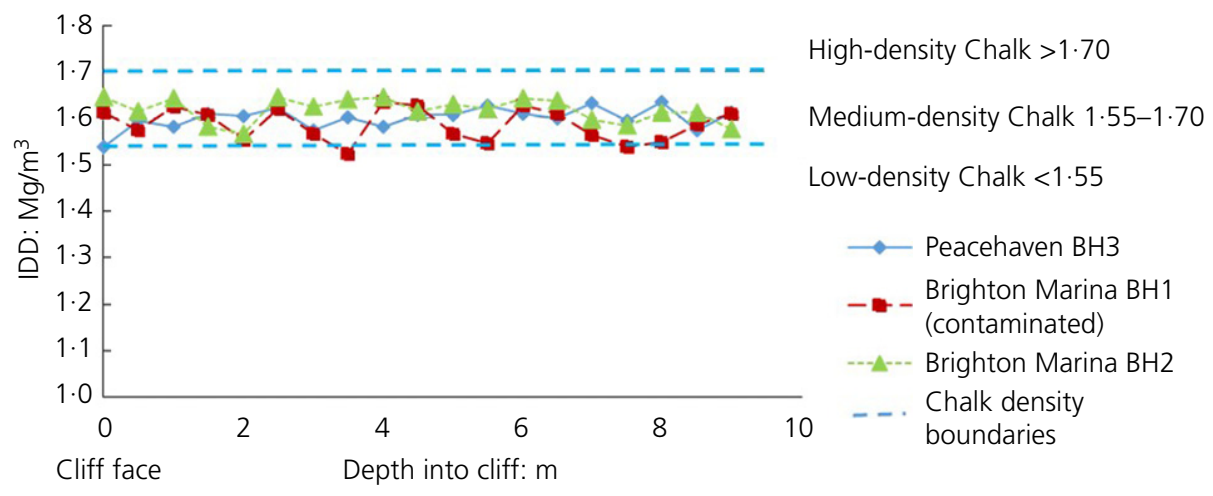

Figure 9. IDD plotted against horizontal depth in to the cliff for the three core runs, based on published chalk density procedures (Lord et al., 2002)

Table 2. IDD for each borehole and the average SD

\begin{tabular}{|c|c|c|c|c|c|c|}
\hline & \multicolumn{2}{|c|}{ Brighton $\mathrm{BH} 1$} & \multicolumn{2}{|c|}{ Brighton $\mathrm{BH} 2$} & \multicolumn{2}{|c|}{ Peacehaven BH3 } \\
\hline & Average & Average SD & Average & Average SD & Average & Average SD \\
\hline IDD: $\mathrm{Mg} / \mathrm{m}^{3}$ & $1 \cdot 59$ & 0.03 & $1 \cdot 62$ & 0.02 & $1 \cdot 60$ & 0.02 \\
\hline
\end{tabular}


UCS varying from around $1.5 \mathrm{MPa}$ near the cliff face to $3.8 \mathrm{MPa} 7 \mathrm{~m}$ behind the cliff face. Both Brighton cores (BH1 and $\mathrm{BH} 2$ ) also showed increases in UCS, ranging from 1.85 MPa near the cliff face to $2.95 \mathrm{MPa} 7-8 \mathrm{~m}$ behind the cliff face (Figure 10). In all cases the cores showed a rapid decrease in rock strength near the cliff face, with samples near the cliff face only retaining $40-50 \%$ of the intact rock strength compared with the samples $7-8 \mathrm{~m}$ in horizontal depth behind the cliff face. While there was some variability in the results, the best-fit lines clearly show a trend of a decrease in strength towards the cliff face (Figure 10), with both Brighton Marina boreholes having very similar best-fit lines. It is likely this trend is at least in part due to salt water weakening but may also be related to a number of other factors.
The higher UCS results are consistent with the literature for saturated Chalk samples when plotted against the IDD of Chalk (Figure 11). The lower UCS results were slightly lower than the value reported by Matthews and Clayton (1993), but this could be expected due to the weakening within the samples nearer the cliff face. Therefore, the UCS test results for the cores deep within the cliff compared favourably to the existing literature, but the samples nearer the cliff face were much weaker.

\subsection{Geochemical analysis}

The results from the geochemical analysis consisted of chloride and sulfate concentrations (measured in $\mathrm{mg} / \mathrm{l}$ ). Figure 12 shows the relationship between chloride concentration and depth behind the cliff face for the two research sites. Dittmar's law states that the major chemicals that constituent sea water are

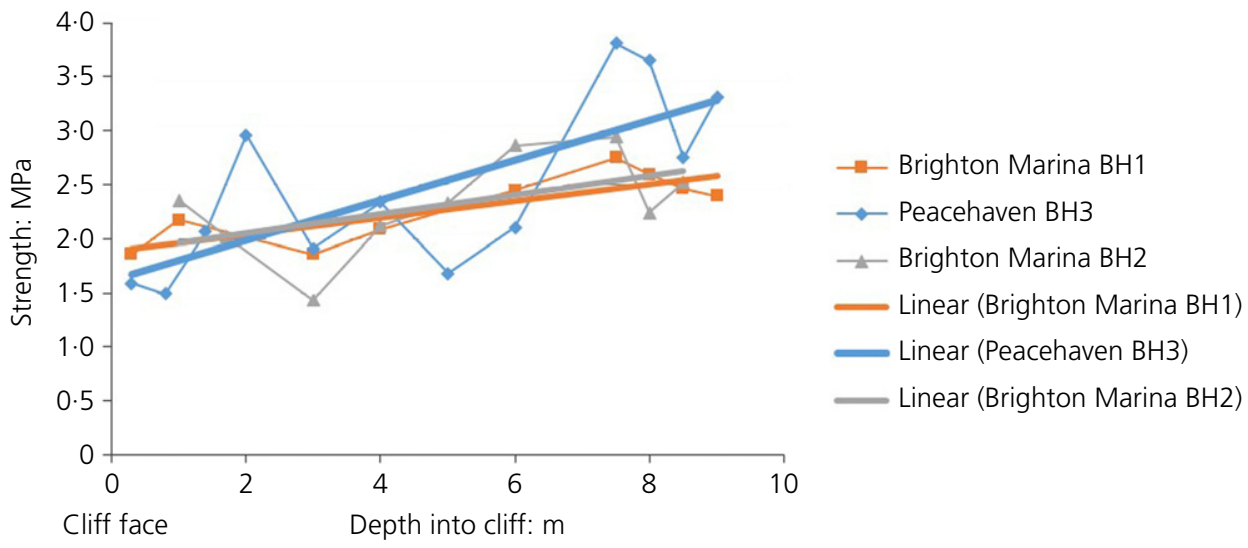

Figure 10. Variation in UCS with horizontal distance into the cliff for the three core runs

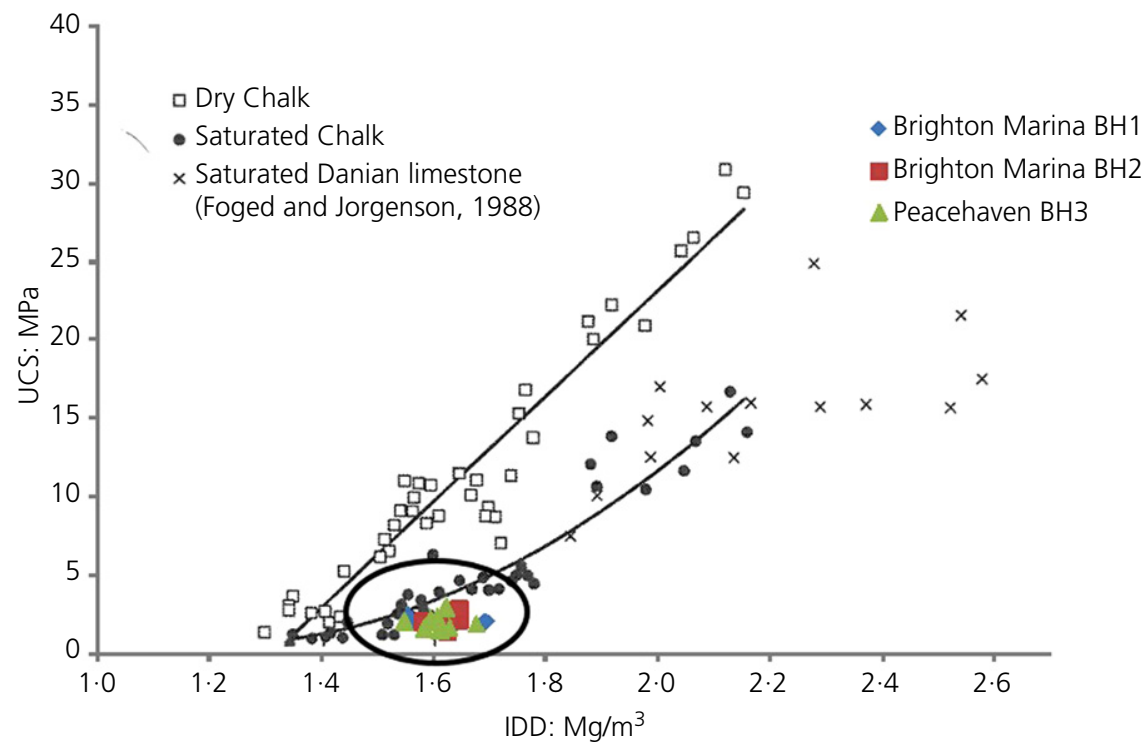

Figure 11. Comparison of UCS and IDD from this study and results from Matthews and Clayton (1993), adapted from Mortimore et al. (2004a) 


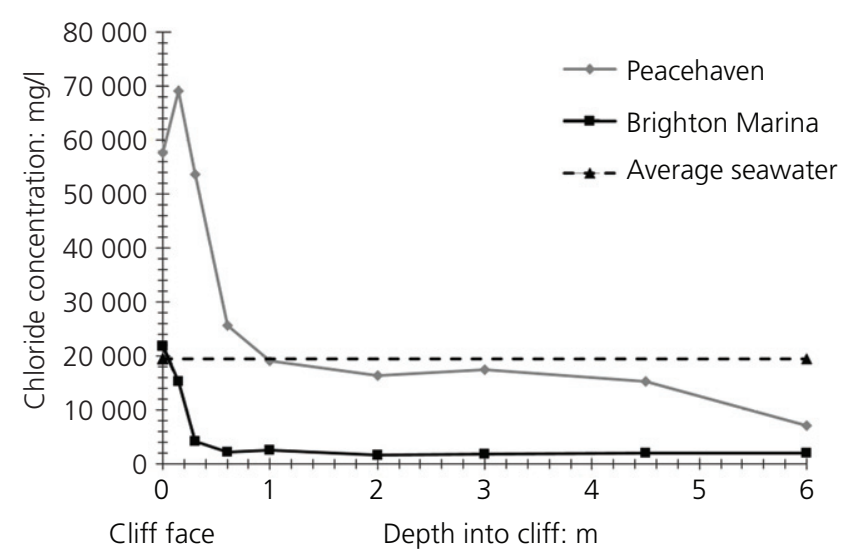

Figure 12. Relationship between chloride concentration of pore waters and distance into the cliff. The chloride concentration of sea water is $19345 \mathrm{mg} / \mathrm{l}$

constant. This was later refined by Lyman and Fleming (1940), who identified that chloride concentrations directly reflect the amount of sodium chloride $(\mathrm{NaCl})$ derived from sea water; therefore, chloride concentration can be converted to a salt concentration - the chloride concentration is 55\% (19 $345 \mathrm{mg} / \mathrm{l})$ of the total salts in sea water and so can be converted to salt concentration by multiplying by 1.804 . This method assumes that there are not large amounts of other chloride species existing in pore waters, but this is unlikely in sea water.

Figure 12 shows that elevated chloride concentrations were found in the cliff at both research sites. At Brighton Marina, the chloride concentrations peaked at $21674 \mathrm{mg} / \mathrm{l}$, levelling out to around $1850 \mathrm{mg} / \mathrm{l}$ at $0.6 \mathrm{~m}$ behind the cliff face and continuing at this concentration for the next $5 \mathrm{~m}$; hence it can be assumed that this concentration reflects the background groundwater concentrations of chloride. By contrast, at the Peacehaven site (BH3), the chloride concentration chloride peaked at $69075 \mathrm{mg} / \mathrm{l}$ and had still not levelled out $6 \mathrm{~m}$ behind the cliff face. Thus, salt from the sea water in the exposed section of cliff penetrated in excess of $6 \mathrm{~m}$, unlike at Brighton Marina where the penetration was only $0.6 \mathrm{~m}$ before reaching a baseline. The results in Figure 12 show that chloride concentrations in the Peacehaven core were much higher than those of the Brighton Marina cores. The reason for the difference between the sites is likely to be the coastal cliff protection present at the Brighton site and absent at Peacehaven. At Peacehaven, the cliff is exposed to wave impact at high tides, storm surges, sea spray and capillary action where saline water is drawn up from the water table below. Due to the coastal protection at Brighton Marina, direct contact with sea water is limited, sea spray only occurs in stormy conditions and, given the results, it is unlikely that capillary action is a factor in salt saturating pore waters. In both Brighton Marina cores (BH1 and $\mathrm{BH} 2$ ) and the Peacehaven core (BH3), the maximum chloride concentrations were higher than those of the sea

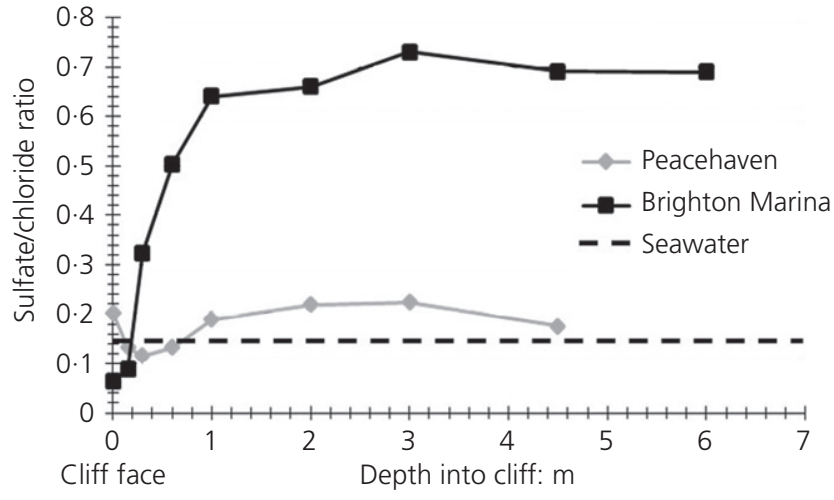

Figure 13. Relationship between sulfate/chloride ratio and distance into the cliff (an error occurred at $6 \mathrm{~m}$ with the measurement of the sulfate sample at Peacehaven so it could not be calculated)

water, showing that salt from sea water is concentrating in the Chalk pores.

In general, the chloride concentrations were highest near the cliff face before dropping off. The Peacehaven core (BH3) had elevated levels of chloride that continue throughout the tested section of the borehole. Testing was stopped at $6 \mathrm{~m}$ depth because it was not expected that chloride would penetrate the Chalk to this depth.

Comparison of the sulfate to chloride ratio can be used as an indicator of the groundwater regime and the origin of the pore water. Figure 13 shows the relationship between this ratio and the distance behind the cliff face for each site.

The Peacehaven pore water curve (Figure 13) shows a sulfate/chloride ratio that initially fluctuates close to that of sea water, with chloride concentrations of around $17000 \mathrm{mg} / \mathrm{l}$, before increasing slightly and then dropping off again. At Peacehaven, for at least $4.5 \mathrm{~m}$ into the cliff, sea water dominates the groundwater conditions with local groundwater having a minor influence on the sulfate/chloride ratio.

The Brighton Marina site shows a trend from sulfate/chloride ratio close to that of sea water near to the cliff face, followed by an initial increase in sulfate concentrations until the sulfate/chloride ratio settles at around $0 \cdot 7$. The natural groundwater sulfate/chloride ratio for Chalk in southeastern England is around 0.76 (Edmunds et al., 2003); this confirms that, at Brighton Marina, sea water dominates the first metre into the cliff and thereafter the local groundwater dominates the pore waters.

\section{Discussion}

The strength test results showed that at both the protected and unprotected localities, the Chalk at the cliff face only retained 
$40-50 \%$ of its typical intact rock strength and the strength increased rapidly over a $7-8 \mathrm{~m}$ depth interval behind the cliff face where the UCS was close to that expected for Newhaven Chalk of this density (Matthews and Clayton, 1993; Figure 11). Cores from the natural unprotected cliff section at Peacehaven showed the greatest loss in strength, while both Brighton cores showed very consistent UCS trends ranging from 1.85 MPa near the cliff face and increasing to 2.95 MPa at $7-8 \mathrm{~m}$ behind the cliff face. Analyses of core pore water chemistry from the cliff face at both localities showed elevated concentrations of salt penetrating the cliffs, with the salt concentrating to depths greater than $6 \mathrm{~m}$ at Peacehaven. Geochemical analysis revealed that chloride concentrations in the Peacehaven core were elevated throughout the core and tests identified sea water as the origin; this core showed the greatest reduction in strength. The Brighton Marina cores only showed elevated chloride concentrations in the first $0 \cdot 6-1 \cdot 0 \mathrm{~m}$ and the pore waters beyond indicated groundwater origin.

Among the possible processes that contribute to weakening of the Chalk in coastal cliffs, concentrations of salt in the pores are likely to be one, and this link was demonstrated by Lawrence et al. (2013). However, as shown in Figure 10, there is not a straight correlation between Chalk weakening and salt content, so it is likely that other coupled processes act to weaken Chalk near cliff faces. These could include the following.

- Heterogeneity in the rock material. Mortimore and Pomerol (1998) and Mortimore et al. (2004a) demonstrated that Chalk can vary, even within a single block. This can be related to sedimentation, bioturbation and diagenesis, which may affect the physical properties of Chalk such as strength, with weaker, softer Chalks being more susceptible to erosion.

- Wave cut notch development and over-steepening off the cliff as a result of wave and shingle action attacking the base of the cliff, leading to failure, as demonstrated by Hutchinson (1972). However, significant portions of the studied cliff are not exposed to wave action and notches do not develop, especially along protected sections, but this does not eliminate cliff failures (see Figure 1) (Mortimore et al., 2004b; Stavrou et al., 2011).

- Fracture development leading to long-term changes in the stress regime. These may be primary faults or fractures, orientated at a variety of angles to the cliff face, or relatively new tension fractures formed during cycles of cliff recession, sub-parallel to the cliff face. Eventually, these will lead to fracture-controlled failures. Fractures can also control the size and type of failure in Chalk (Duperret et al., 2004; Mortimore et al., 2004b). Rock slope fracture-led failures are a combination of discontinuity geometry and rock strength (particularly cohesion $(c)$ and friction $(\phi)$ ).

- Climatic controls. Rock strength is not usually considered to be temporally variable and so is rarely considered in relation to climate change. However, this is not true for soft rocks such as Chalk, which can weaken and weather over short time periods as they are exposed to external factors. Benavente et al. (2008) expect salt weakening to worsen throughout the UK as a result of drier summers, wetter winters, more storms and changes in humidity, which are associated with changes in pore suction properties.

If it is accepted that Chalk is weaker at the cliff face and for several metres into the cliff, the effect this has on cliff erosion and/or cliff instability needs to be considered. As emphasised by Lawrence et al. (2013), weakening of Chalk material is a key process in the instability of Chalk cliffs. They attributed this largely to water and salt water weakening of the Chalk, but it is likely that multiple coupled processes are involved, including those listed above.

The laboratory index test results demonstrated that the Chalk throughout the length of the borehole was fully saturated; therefore, it can be assumed that water weakening has occurred and, additionally, the Chalk has undergone salt water weakening where high concentrations of salt were observed. Lawrence et al. (2013) found that salt-saturated samples of Seaford Chalk, tested triaxially to simulate conditions at the base of a cliff, lost on average $40 \%$ of their strength compared with samples from inland quarries where there was no salt water. These observations compare favourably to the loss of strength in the core samples along the paths of the three horizontal boreholes tested in this study, with salt water penetration into the cliff face in both protected and unprotected cliff sections contributing to weakening.

Styles et al. (2011) demonstrated that Chalk cliff failures are dependent on the rock mass strength, wave cut notches and temporal factors, and it is likely salt water weakening affects and enhances all of these mechanisms. With sea water penetrating, saturating and concentrating in coastal Chalk cliffs, this will lead to chemical and mechanical weakening. When this is then coupled with other coastal processes in the form of saturation from sea water, wave and shingle attack, wave cut notch development, over-steepening off the cliff, fracture development and climatic controls it is likely to lead to increased erosion, which in turn hastens cliff failure as the stress regimes change in the overlying cliff which has itself been weakened by multiple responses including water and salt water weakening. It is likely that the penetration/presence of high concentrations of salt in Chalk pore water acts as a catalyst enabling all the other established processes to be enhanced.

\section{Conclusions}

The field observations and laboratory results obtained in this study illustrate the role of salt water in the weakening of Chalk especially close to the cliff face. The key outcomes of this work are as follows. 
The Chalk was fully saturated along the entire length of all cores, suggesting that the Chalk pores are permanently saturated.

- Salt was concentrated in the pore water of Chalk cliffs in direct or indirect contact with the sea (sea water, salt spray).

- The origin of the salt found in the Chalk pores was from sea water.

- Salt is concentrating at depths greater than $6 \mathrm{~m}$ along unprotected sections of cliffs - deeper than previously considered.

- Chalk cores from the horizontal boreholes showed a decrease in rock strength, with samples near the cliff face only retaining $40-50 \%$ of the intact rock strength compared with samples taken at 7-8 m horizontal depth behind the cliff face; this has not previously been reported.

- UCS test results for cores deep within the cliff compared favourably with other published results. However, the samples nearer the cliff face were much weaker (Figure 11) and therefore density/strength correlations are misleading unless the pore water chemistry is known.

- The Peacehaven core, from the unprotected exposed site, showed the greatest salt concentration and depth of penetration into the cliff. This was also associated with the greatest loss of strength.

The results of this work revealed the salt concentrations in Chalk pore water and concomitant UCS reductions within coastal cliffs. This suggests that it is likely that coastal cliff rock failures will be influenced by salt water weakening. Further research is required to show how much influence this process has on cliff instability.

\section{Acknowledgements}

This work was supported by Brighton and Hove City Council as part of the INFORM (INformation FOr cliff Recession Management) project. The work was carried out at the Geoenvironmental Laboratory of the University of Leeds; the authors express thanks to Mr Kirk Handley.

\section{REFERENCES}

Austad T, Strand S, Maland MV, Puntervold T and Kornes KS (2008) Seawater in chalk: an EOR and compaction fluid. SPE Reservoir Evaluation and Engineering 11: 648-654.

Benavente D, Brimblecombe P and Grossi CM (2008) Salt weathering and climate change. In New Trends in Analytical, Environmental and Cultural Heritage Chemistry (Colombini MP and Tassi L (eds)). Transworld Research Network.

BSI (1990) BS 1377-2:1990: Methods of test for soils for civil engineering purposes. BSI, London, UK.

BSI (2009) BS EN ISO 14689-1:2003: Geotechnical investigation and testing - identification and classification of rock - part 1 : identification and description. BSI, London, UK.

Budetta P, Galietta G and Santo A (2000) A methodology for the study of the relation between coastal cliff erosion and the mechanical strength of soils and rock masses. Engineering Geology 56: $243-256$
Busby JP, Lawrence JA, Senfaute G et al. (2004a) PRediction of the Erosion of Cliffed Terrains 'PROTECT': Technical Report. British Geological Survey, Nottingham, UK, Internal Report IR/04/142

Busby JP, Senfaute G, Gourry JC et al. (2004b) Developing tools for the prediction of catastrophic coastal cliff collapse. Proceedings of the 7th International Symposium - Delivering Sustainable Coasts: Connecting Science and Policy, Aberdeen, UK, pp. 596-601.

Delage P, Schroeder C and Cui YJ (1996) Subsidence and capillary effects in chalks. Proceedings of EUROCK '96, Prediction and Performance on Rock Mechanics and Rock Engineering, Turin, Italy, vol. 2, pp. 1291-1298.

Dornbusch U (2015) Comment on: Lawrence J.A., Mortimore, R.N., Stone, K. \& Busby J. 2013. Sea salt water weakening of chalk and the impact on cliff instability, Geomorphology, 191, 14-22. Geomorphology 231: 390-392.

Duperret A, Genter A, Martinez A and Mortimore RN (2004) Coastal chalk cliff instability in NW France: role of lithology, fracture pattern and rainfall. In Coastal Chalk Cliff Instability (Mortimore RN and Duperret A (eds)). Geological Society, London, UK, Engineering Geology Special Publication 20, pp. $33-56$

Duperret A, Taibi S, Mortimore RN and Daigneult M (2005) Effect of ground water and sea weathering cycles on the strength of chalk rock from unstable coastal cliffs of NW France. Engineering Geology 78: 321-343

Edmunds WM, Shand P, Hart P and Ward RS (2003) The natural (baseline) quality of groundwater: a UK pilot study. Science of the Total Environment 310: 25-35.

Goudie A, Cooke R and Evans I (1970) Experimental investigation of rock weathering by salts. The Royal Geographical Society 2(4): 42-48.

Heggheim T, Madland MV, Risnes R and Austad T (2005) A chemical induced enhanced weakening of chalk by seawater. Journal of Petroleum Science and Engineering 46: 171-184.

Hellmann R, Renders PJN, Gratier JP and Guiguet R (2002) Experimental pressure solution compaction of chalk in aqueous solutions part 1 Deformation behaviour and chemistry. In Water-Rock Interaction, Ore Deposits, and Environmental Geochemistry: A tribute to David A. Crerar (Hellman R and Wood SA (eds)). Geochemical Society, Washington, DC, USA, Special Publication 7, pp. $129-152$.

Hutchinson JN (1972) Field and laboratory studies of a fall in upper chalk cliffs at Joss Bay, Isle of Thanet. Stress strain behaviour of soils. In Proceedings of the Roscoe Symposium. G. T. Foulis \& Co. Ltd, Cambridge, UK, pp. 692-706.

Lawrence JA and Mortimore RN (2015) Reply to comment on: Lawrence, J.A., Mortimore, R.N., Stone, K.J. and Busby, J.P., 2013. Sea salt water weakening of chalk and the impact on cliff instability, Geomorphology, 191, 14-22. Geomorphology 231: 393-394.

Lawrence JA, Mortimore RN, Stone K and Busby J (2013) Sea salt water weakening of chalk and the impact on cliff instability Geomorphology 191: 14-22.

Lord JA, Clayton CRI and Mortimore RN (2002) The Engineering Properties of Chalk. Construction Industry Research and Information Association, London, UK, Publication C574.

Lyman J and Fleming RH (1940) Composition of sea water. Journal of Marine Research 3: 134-146.

Matthews MC and Clayton CRI (1993) Influence of intact porosity of the engineering properties of weak rock. In Geotechnical Engineering of Hard Soils - Weak Rocks (Anagnostopouos A, Sclosser F, Kalteziotis N and Frank R (eds)). Balkema, Rotterdam, the Netherlands, vol. 1, pp. 693-702. 
Mortimore RN and Fielding PM (1990) The relationship between texture, density and strength of chalk. In Chalk, Proceedings of the International Chalk Symposium (Burland JB, Mortimore RN, Roberts LD, Jones DL and Corbett BO (eds)). Thomas Telford, London, UK, pp. 109-132.

Mortimore RN and Pomerol B (1998) Basin analysis in engineering geology: chalk of the Anglo-Paris Basin. In Proceedings of the 8th International Congress International Association for Engineering Geology and the Environment, Vancouver (Moore D and Hungr O (eds)). Balkema, Rotterdam, the Netherlands, pp. 3249-3268.

Mortimore RN, Stone KJ, Lawrence JA and Duperret A (2004a) Chalk physical properties and cliff instability. In Coastal Chalk Cliff Instability (Mortimore RN and Duperret A (eds)). Geological Society, London, UK, Engineering Geology Special Publication 20 , pp. $75-88$.

Mortimore RN, Lawrence JA, Pope D, Duperret A and Genter A (2004b) Coastal cliff geohazards in weak rock: the UK Chalk cliffs of Sussex. In Coastal Chalk Cliff Instability (Mortimore RN and Duperret A (eds)). Geological Society, London, UK, Engineering Geology Special Publication 20, pp. 3-31.

Risnes R, Madland MV, Hole M and Kwabiah NK (2005) Water weakening of chalk - mechanical effects of water-glycol mixtures. Journal of Petroleum Science and Engineering 48: 21-36.

Robinson DA and Jerwood LC (1987) Frost and salt weathering of chalk shore platforms near Brighton, Sussex, UK. Transactions of the Institute of British Geographers 12: 217-226.

Spence MJ, Thornton SF, Bottrell SH and Spence KH (2005)

Determination of interstitial water chemistry and porosity in consolidated aquifer materials by diffusion equilibrium-exchange. Environmental Science and Technology 39: 1158-1166.

Stavrou A, Lawrence JA, Mortimore RN and Murphy W (2011) A geotechnical and GIS based method for evaluating risk exposition along coastal cliff environments: a case study of the chalk cliffs of southern England. Natural Hazards and Earth System Sciences 11: 2997-3011.

Styles TD, Coggan JS and Pine RJ (2011) Back analysis of the Joss Bay Chalk Cliff Failure using numerical modelling. Engineering Geology 120: 81-90.

Sunamura T (1994) Rock control in coastal geomorphic processes. Transactions of the Japanese Geomorphological Union 15: 253-272. Thorne CR, Evans EP and Penning-Rowsell EC (2007) Future Flooding and Coastal Erosion Risks. Thomas Telford, London, UK.

Trenhaile AS (1987) The Geomorphology of Rock Coasts. Clarendon Press, Oxford, UK. 